\title{
VULNERABILITY ASSESSMENT IN MEGALOPOLIS: ANP_MAS MODELING APPROACH FOR MEXICO CITY
}

\begin{abstract}
We present here the advances in the development of the MEGADAPT model (MEGAcity-ADAPTation model). MEGADAPT simulates the dynamic interactions underling Mexico City's vulnerability to socio-hydrological risks. The ANP is used to (1) depict the mental models that determine the actions of diverse social actors, and (2) develop the decision rules to be incorporated into an multi-agent based model (MAS).
\end{abstract}

Keywords: flood, urban sprawl, risk, socio-ecological systems.

\section{Introduction}

Urban environments are complex systems with multiple social and physical subcomponents operating and interacting at multiple spatial and temporal scales. This complexity challenges efforts towards reducing the vulnerability of megacities in developing world to increasing flooding, chronic water scarcity and associated health outcomes in the context of climatic change. Megacities are climate-change hotspots, and among them, Mexico City has been identified as one of the more critical sites for climate impacts. In this paper we present the integration of the ANP and Multi-Agent Based Model (MAS) to simulate potential scenarios of governance of water resources and assess socio-ecological vulnerability to water-related hazard events in Mexico City.

\section{Literature Review}

The integration of geographic information systems, MCDM and MAS is a relatively novel approach to solve multi-objective problems in urban and rural environments (Manson 2005, Moglia et al 2010, Sabri et al. 2011). While combining MCDA method with MAS have been use to assess the effect of decision of managers and users on the management of natural resources in rural settings, they rarely been use to assess socioecological vulnerability urban environments

\section{Objectives}

This project integrates biophysical system modeling with in-depth analysis of the motivations and responses of distinct subsets of Mexico City's diverse population to this risk into an integrated, dynamic systems model: the MEGADAPT model (MEGAcityADAPTation model). This integration is based on geo-referenced multi-criteria decision- 
analysis (GIS-MCDA) and MAS, supported by survey data and participatory activities with key decision-makers.

\section{Methodology}

The MEGADAPT model will simulate three critical symptoms of increasing dysfunction in Mexico City's water system: chronic flooding, water scarcity, and the public health consequences of contaminated water. In essence, we link the biophysical-infrastructural system and the social-institutional system and related "mental models" The ANP is used to elicit these models in terms of the rules, norms and regulations that govern their agents ' actions (Figure 1). The ANP depicts how agents perceive, prioritize respond, and ultimately affect the biophysical-technical system that in turn drives vulnerability outcomes, whereas a hybrid multi-agent based model will account for the agency of the actors as well as the temporal dynamics of vulnerability drivers and attributes.
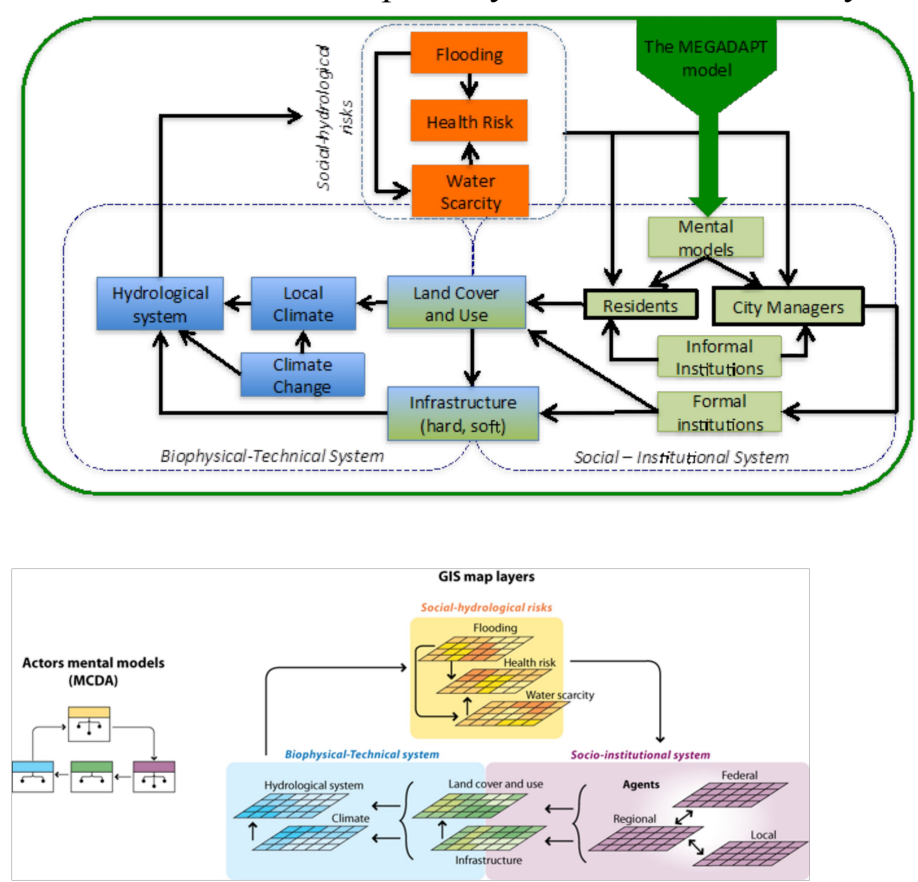

\section{Conclusions}

MEGADAPT aims to simulate potential scenarios of governance of water resources and assess socio-ecological vulnerability to water-related hazard events in Mexico City. The ANP is an effective tool not only for determining the weights of MEGADAPT parameters in every simulation time for the MAS, but also for providing a thorough understanding of both intangible and tangible criteria underlying societal actions.

\section{Key References}

Manson, Steven M. 2005. "Agent-Based Modeling and Genetic Programming for Modeling Land Change in the Southern Yucat??n Peninsular Region of Mexico." Agriculture, Ecosystems and Environment 111 (1-4): 47-62. 
ISAHP Article: A Style Guide for Paper Proposals To Be Submitted to the International Symposium on the Analytic Hierarchy Process 2016, London, U.K.

doi:10.1016/j.agee.2005.04.024.

Moglia, Magnus, Pascal Perez, and Stewart Burn. 2010. "Modelling an Urban Water System on the Edge of Chaos." Environmental Modelling \& Software 25 (12). Elsevier Ltd: 1528-38. doi:10.1016/j.envsoft.2010.05.002.

Sabri, S., Ludin ANMM, Ho CS. 2011. Conceptual design for an integrated geosimulation and analytic network process (ANP) in gentrification appraisal. Applied Spatial Analysis doi:10.1007/s12061-011-9069-5 